LSP International Journal, Vol. 7, Issue 1, 2020, 135-146

(C) Universiti Teknologi Malaysia

E-ISSN 2601-002X

DOI: https://doi.org/10.11113/lspi.v7n1.102

\title{
Innovative Flipped Classroom Approach for TESL Subjects: From Students' Perspective
}

\author{
Chu Shean Yin \\ SMK Bahau, Negeri Sembilan \\ Masdinah Alauyah Md.Yusof \\ Language Academy, Universiti Teknologi Malaysia, 81310 UTM Johor Bahru, Johor, Malaysia \\ Submitted: 10/01/2020. Revised edition: 25/06/2019. Accepted: 28/06/2020. Published online: 30/06/2020
}

\begin{abstract}
The importance of active learning and higher order thinking skills among students at higher learning institutions have steered lecturers to employ the flipped classroom approach in their classes. The move is hoped to assist students to become active recipients of knowledge and break away from the traditional learning method where knowledge is only imparted by lecturers. A study was conducted to investigate: (1) the TESL students' ability to research and present their findings related to a teaching method via group posters when the flipped classroom approach is utilized in their Methodology in TESL 1 subject, and (2) their views on the feasibility of using flipped classroom approach for other TESL subjects. This study had adopted the mixed method approach in which an interview guide was used to address the first research question and a questionnaire was used to address the second research question. From the interview, it is found that majority of the TESL students had managed to research the teaching method assigned to them, had understood what they were reading, and were able to present the teaching method in the form of a poster. From the questionnaire data, it was found that majority of the TESL students agreed the flipped classroom approach can be implemented for other TESL subjects although a few of them felt that it might only be suitable for certain topics or subtopics as they were afraid of inaccurate knowledge being transferred if there is no proper guidance from the lecturer. Nevertheless, for this study, it can be concluded that the flipped classroom approach had enhanced the students' understanding of the given topic, and it is feasible for other TESL subjects.
\end{abstract}

Keywords: Flipped classroom approach, TESL, knowledge transfer

\subsection{INTRODUCTION}

In many public and private higher learning institutions, according to Danker (2015, p.173), who did a research on 'Using Flipped Classroom Approach to Explore Deep Learning in Large Classroom' in Malaysian tertiary education institutions, the teacher-centred learning approach is still widely used and preferred in many developing countries, including Malaysia.

\footnotetext{
*Correspondence to: Masdinah Alauyah Md.Yusof (email: alauyah@utm.my)
} 
This lecture-based instruction or teacher-centred approach has somehow encouraged students to become passive recipients of knowledge, and to be inactive learners where they would listen passively to the lecture, jot down notes, chat with their friends or amuse themselves with their phones. In addition, since there is usually no assessment at the end of the lesson to test their understanding, some students seldom take the initiative to participate in the classroom discussions. It is believed that these students' inactive participation could greatly influence their academic performance and could affect the quality of their learning in schools if they could not properly grasp the essence of the lesson from the lectures. Moreover, it is difficult to determine if these students were able to digest the given knowledge or construct new knowledge from the lesson taught.

The spoon-feeding culture which has been a dominant educational paradigm ever since students were in kindergarten, primary and secondary schools, and at times, in the tertiary institution, could also be the factor making them be irresponsible for their own learning or be inactive in meaningful learning. Due to this factor, students might not even use their creativity and critical thinking skills to polish their lifelong learning skills. This spoon-feeding culture obviously is not consistent with the National Higher Education Action Plan 2007-2010 proposed by the Ministry of Education where lifelong learning is something that students cannot be lacking in (Grapragasem et al., 2014). Hence, Donnelly (2009) encouraged tertiary institutions to incorporate the use of technology in their academic strategic planning, and in accommodating students of different cultural backgrounds. The paradigm shift should take place in higher institutions; changing from the lecturebased instruction model to a student-centred model with the integration of technology as a tool for teaching and learning. The Flipped Classroom Approach, a current student-centred model which comes under the blended learning umbrella, could reform the traditional teaching and learning approach to integrate both online and face-to-face settings (Danker, 2015). Turan \& Akdag-Cimen (2019), who conducted a review of flipped classroom approach in English language classrooms, also reported that the use of flipped classroom approach was workable especially for the speaking and writing skills. Nevertheless, although previous studies including by Andujar et al. (2020) have indicated the benefits gained by students in a flipped classroom, studies conducted by Vuong (2018) and Miragall \& García-Soriano (2016) have shown that students often face challenges in participating in the flipped classroom setting.

Hence, this study was conducted to investigate the TESL students' ability to research and present information related to a language teaching method when the flipped classroom approach is utilized in their Methodology in TESL 1 class, and to investigate their views regarding the possibility of using the flipped classroom approach to teach other TESL subjects.

\section{BACKGROUND OF THE STUDY}

Flipped classroom approach is an innovation to teaching and learning; it is also known as the inverted classroom (Gannod et al., 2008; Lage, Platt, and Treglia, 2000) whereby the school work, particularly learning through lecture, is done at home in the offline mode whereas the home work or assignments 
are conducted at school (Flipped Learning Network, 2014). For instance, the students can be asked to read an assigned and self-selected topic, or watch a video outside of the classroom, and later they could discuss the topic in pairs, groups or as a whole class inside the classroom. However, there is no rigid definition for flipped classroom approach. In general, it simply means the learning task is given to students to carry out outside the classroom and it is followed by collaborative work inside the classroom.

Although the classroom is flipped, flipped learning will not necessarily take place if the teacher does not incorporate the following four pillars into their teaching; i.e. Flexible Environment, Learning Culture, Intentional Content and Professional Educator (Flipped Learning Network, 2014). In the flexible learning environment, the teacher will have to decide how a particular lesson will be carried out; be it an individual work, pair work or group work will depend on the class size and the objectives of the lesson. In addition, the teacher will have to allow various learning modes as well as flexible time and pace for students to work on the task given to them. The teacher will then have to monitor the students' progress on the task from time to time and suggest appropriate improvements. This learning culture is a paradigm shift from the teacher-centred classroom to student-centred classroom. The in-class time is utilised for in-depth learning of the topic so as to generate rich learning experiences where students are required to actively construct their own new knowledge through the meaningful events and scaffoldings given by the teachers. With this learning approach, it is possible to cultivate the students' independent learning habits because they are to complete a task on their own. In relation to intentional content, the teachers need to think of how they can effectively adopt the flipped classroom approach to help students master the conceptual theory of a topic and the procedural fluency. In other words, the teachers have to know and differentiate what to be taught in classroom and what the students should research and learn outside of the classroom. In this way, the teacher can utilise the in-class time to the fullest and thus, create active and meaningful learning sessions for the students. Finally, as a professional educator, the teachers have to be approachable and available to all students regardless of their role in doing a task; either as an individual or a group member. The teacher must also conduct a formative assessment consistently via observation during class time for future improvement, and keep abreast with the latest information via interaction and reflection with other teachers so as to improvise their current practices.

However, flipping the classroom is not just a matter of imparting knowledge to students via watching videos, but it has, in fact, been proven to increase learners' participation, motivation, critical thinking, communication skills, and interest in EFL classrooms; otherwise, it would make the teaching and learning process meaningless (Muldrow, 2013). In addition, Kawinkoonlasate (2019) stated that with this approach, EFL students will have more time to engage in problem-solving activities, discussion and analysis. The profusion benefits of the flipped classroom approach to students has encouraged many universities in Malaysia to implement it in the classroom; lecturers are gradually embedding this approach in their classes.

The Teaching English as a Second Language (TESL) program in the chosen university is a four-year undergraduate program where students are required to complete seven semesters of coursework and undergo one semester of practical teaching during their sixth semester of study. The TESL students in this program are required to complete the English language teacher training subjects as their major and the Multimedia subjects as their minor as well as the counselling and 
educational psychology subjects. The English language teacher training subjects are divided into pure English language studies subjects such as Linguistics, Discourse Analysis, and Structure of English while the Education subjects are Methodology in TESL 1 and 2, Human Development of Teachers, Micro and Macro Teaching. All the subjects are meant to develop the TESL students' hard skills which are the knowledge as well as the soft skills which are teaching skills and leadership skills so as to prepare them to be holistic teachers who can serve the country and community in the future. As for the Methodology in TESL 1 subject that was used as the setting of this study, it is one of the Education subjects that exposes students to the foundation of teaching such as the classroom management, lesson planning, roles of the teachers, various approaches to teaching methodology and others. The subject aims to empower the TESL students to have an overview on what it takes to be a teacher in the school.

With the increasing popularity of blended and online learning, the flipped classroom approach is being experimented in the TESL undergraduate program to find out its feasibility in making the teacher training more meaningful for the TESL students. As a matter of fact, the unprecedented recent Covid19 event has encouraged transformative pedagogies including the flipped classroom approach to address many of the problems of traditional lecture-based classes (Andujar et al., 2020).

\section{METHODOLOGY}

This study has employed a mixed method research methodology to obtain answers to the research questions mentioned earlier. Creswell et al. (2006) stated that the use of both qualitative and quantitative approaches would help generate more details of the issue being studied. In fact, this study is linked to the Convergent Parallel Design or Concurrent Design of mixed method as suggested by Creswell (2012) where the same priority was given to both the qualitative and quantitative data of this research, and where the data were concurrently collected during this study though analysed individually. The results from the analysis of both the quantitative and qualitative data were merged and the combined results were interpreted.

In this study, for the qualitative data, the semi-structured interview guide was used to investigate the TESL students' abilities to research and present their findings related to a teaching method via group posters for their Methodology in TESL subject. On the other hand, for the quantitative data, the questionnaire was used to obtain the TESL students' views on the feasibility of using flipped classroom approach for other TESL subjects.

The respondents for this study were 23 undergraduate TESL students who were in their third semester of study; four $(17.4 \%)$ were males and nineteen $(82.6 \%)$ were females. All the respondents were selected based on the purposive sampling and they were the whole population of students who enrolled for the Methodology in TESL I subject. The task given by the lecturer was to search for information on different language teaching methodologies and present the findings via group poster presentation. During the presentation, group members will have to explain the language teaching methodology assigned to them when their course mates come around to see their posters. The students 
were also required to answer questions from their course mates. The lecturer, on the other hand, will observe the students' explanations and prompt further questions when necessary. Thus, in order to complete the task, the students were divided into eight groups where each group was to research on the language teaching methodology assigned to them. Each group was to prepare and present a group poster to the class concurrently with the other groups. The division of groups is as in Table 1 below.

Table 1 Group divisions and assigned language teaching method

\begin{tabular}{ll}
\hline Group 1 & Silent Way \\
\hline Group 2 & Total Physical Response (TPR) \\
Group 3 & Task-Based Learning \\
Group 4 & Suggestopedia \\
Group 5 & Audio-lingual Method \\
Group 6 & Direct Method \\
Group 7 & Content-Based Language Teaching \\
Group 8 & Grammar Translation Method \\
\hline
\end{tabular}

All the groups were interviewed using the semi-structured interview questions after the poster presentation. The conversations were audio-recorded with the respondents' consent. After the interview sessions ended, each respondent was requested to complete a questionnaire. The interview responses and questionnaire data collected were later analyzed based on two main themes; namely the TESL students' ability to fulfil the task requirement when the flipped classroom approach is utilized in their Methodology in TESL class and TESL Students' Views on The Feasibility of Using Flipped Classroom Approach to Teach Other TESL Subjects. Figure 1 shows the categorization of themes for the interview and questionnaire data.

\section{RESULTS AND DISCUSSION}

The findings for this study will be discussed based on the themes presented in Figure 1.

TESL Students' Task Fulfilment When Flipped Classroom Approach is utilized in Their Methodology in TESL Class

The TESL students' task fulfilment when the flipped classroom approach is utilized in their Methodology in TESL class will be discussed in relation to their ability to choose the right content for the poster, ability to prepare a poster and ability to present the poster. 


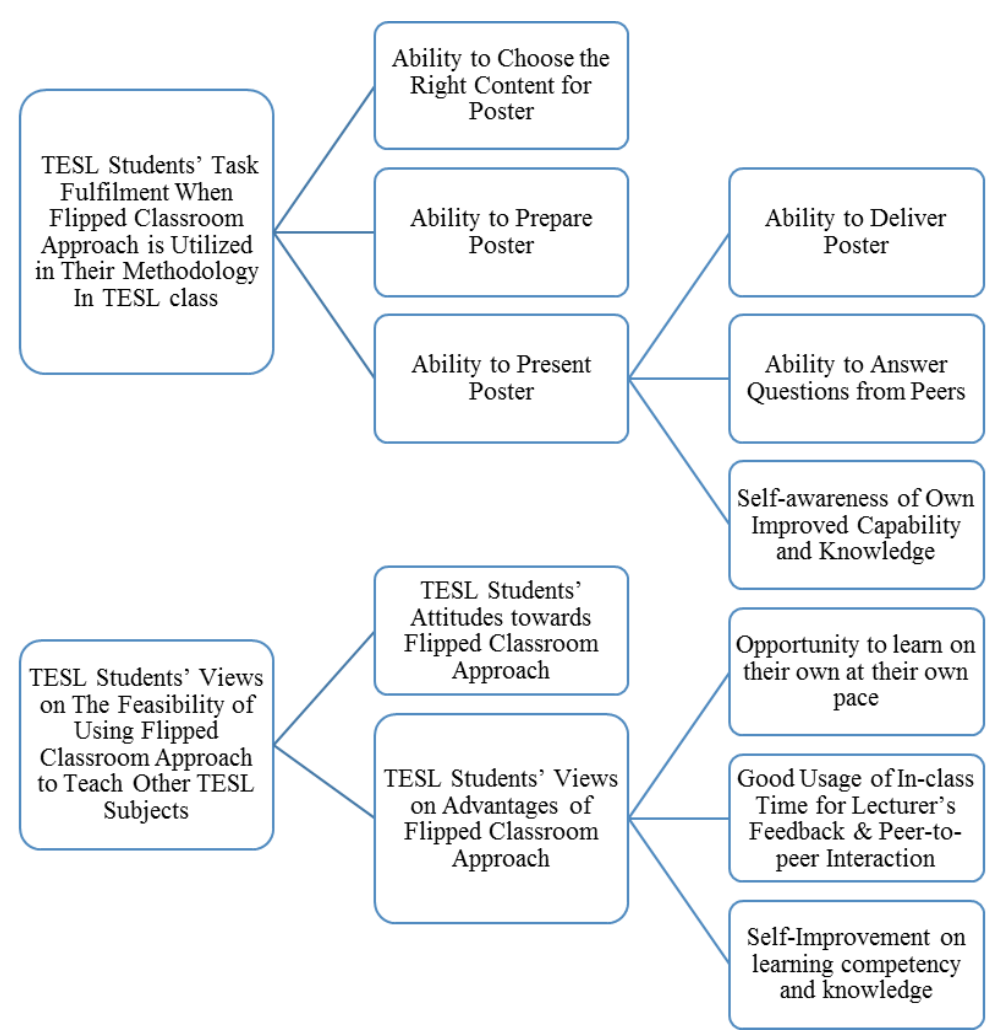

Figure 1 Categorization for interview and questionnaire data

\section{Ability to Choose the Right Content for the Poster}

The TESL students' ability to choose the right content for the poster can be examined through the fulfilment of the given task. In other words, if the students can clearly understand the lecturer's instructions, they would be able to provide the required information to be displayed in the poster. For this subject where the flipped classroom approach is used, the TESL students were given a task to research and present a language teaching method in the form of a poster. The essential information to be included in the poster were the objectives of the method, the characteristics of the method, the teachers' or students' roles including the student-teacher or student-student interactions when the method is employed as well as the pros and cons of the method.

From the analysis of Item 7 in the questionnaire - 'Do you think you have provided all the information required in the assignment?', only 10 students (43.5\%) stated that they have fulfilled the requirement while 13 other students $(56.5 \%)$ said that they might not have provided all the information required for the assignment. When prompted about how the students represented their understandings of the knowledge obtained in their poster, some students stated that they have opted to use cartoons drawings, dialogues and pictures to replace printed words. Table 2 presents the responses given. 
Table 2 Use of visual aids in the poster

\begin{tabular}{ll}
\hline Group 1: Silent Way & Pictures \\
\hline Group 2: Total Physical Response & Pictures \\
Group 3: Task-based Learning & Pictures, Examples \\
Group 4: Suggestopedia & Facts, Examples of music \\
Group 5: Audio lingual & Pictures, Examples \\
Group 6: Direct Method & Pictures, Examples. \\
Group 7: Content-based & Examples with drawings, \\
Group 8: Grammar Translation & Pialogues \\
Method & \\
\hline
\end{tabular}

These above findings revealed that although the students' posters might not have sufficient printed information, their creative posters were actually encouraged by the Cornell Center for Materials Research (n.d.) where it stated that 'less is best!' for the poster presentation. The students claimed that they were able to transfer the obtained knowledge into simple yet interesting posters that represent the group's understanding on an assigned language teaching method.

\section{Ability to Prepare a Poster}

The students' ability to prepare a good poster with appropriate information and visual aids could be gauged in terms of the steps taken to complete the given task. Hence, during the interview, one of the questions the students were asked was to explain what they did to prepare the poster. The analysis of the responses revealed that the first step taken was to delegate tasks among members in the group (refer to Table 3 below).

Table 3 Initial steps taken to prepare the poster

\begin{tabular}{lll}
\hline What did you do to prepare for the poster presentation? & \multicolumn{1}{c}{ Assigning task according to } \\
\hline Group 1: Silent Way & $\begin{array}{l}\text { Asmbers' strengths. } \\
\text { Assigning task according to the } \\
\text { topic. } \\
\text { Assigning task according to the } \\
\text { topic. }\end{array}$ \\
Group 3: Task-based Learning & $\begin{array}{l}\text { Assigning task according to } \\
\text { members' strengths. }\end{array}$ \\
Group 5: Audio lingual & $\begin{array}{l}\text { Search information individually, } \\
\text { find materials and do together. }\end{array}$ \\
Group 6: Direct Method & Assigning subtopics. \\
Group 7: Content-based & Assigning topic \\
Group 8: Grammar Translation & Assigning topic \\
Method & \\
\hline
\end{tabular}


From Table 3, seven groups seemed to start off the assignment by assigning task according to their members' strengths, and according to topics and subtopics related to the assigned language teaching method. One group, however, stated that they started their research by individually searching for information and materials, and then they gathered to share their findings. This finding indicated that the students had clearly understood the given task and were able to divide the research work among themselves in order to find appropriate resources and visual aids related to the language teaching method assigned to them.

The subsequent question asked to gauge the students' ability to prepare a poster was the resources they used to get the necessary information. It was found that all the groups had used articles related to the assigned language teaching method to obtain the needed information from videos, slides, pictures, and websites such as Wikipedia and Blogs (refer to Table 4 below).

Table 4 Resources used to obtain information for the poster

\begin{tabular}{|c|c|}
\hline \multicolumn{2}{|c|}{$\begin{array}{l}\text { 3. What are your resources for the topic given? e.g. online reading, } \\
\text { video }\end{array}$} \\
\hline Group 1: Silent Way & Wikipedia, videos and articles \\
\hline Group 2: Total Physical Response & $\begin{array}{l}\text { Videos, articles, Word Press } \\
\text { (blog) }\end{array}$ \\
\hline Group 3: Task-based Learning & Wikipedia, articles, pictures \\
\hline Group 4: Suggestopedia & Videos, articles and music \\
\hline Group 5: Audio lingual & Videos, articles \\
\hline Group 6: Direct Method & Wikipedia, article, slides \\
\hline Group 7: Content-based & Videos, articles, slides \\
\hline $\begin{array}{l}\text { Group 8: Grammar Translation } \\
\text { Method }\end{array}$ & Videos and articles \\
\hline
\end{tabular}

In summary, it can be concluded that all eight groups had clearly understood the requirement of the given task and they were able to take the necessary steps to prepare and find relevant resources and materials to make their posters informative and interesting.

\section{Ability to Present the Poster}

The last requirement of the task was to display and present the poster. If the students can deliver an effective poster presentation and give good explanation on the assigned language teaching method based on their readings to their peers, it means that they have good understanding of the topic given. In this paper, the students' ability to present the poster will be discussed in terms their ability to deliver the poster, and their ability to answer questions from peers.

The students' ability to verbally and clearly explain the content of their posters and make their audience understand their assigned language teaching method indicated that they had comprehended what they read. In the questionnaire, the students were asked "Can you deliver or interpret the 
information obtained from your readings to your peers effectively during the poster presentation?" Although majority of the students $(95.7 \%)$ stated they could, one student claimed that she could not deliver well. When probed during the interview, this student claimed that she lacked the confident to speak in public. This, however, does not affect the result where majority of the students were able to effectively deliver their understanding of the assigned language teaching method to their peers.

The students' ability to answer questions from their peers with clear explanation and elaboration also denoted they understand of the essential elements of the assigned language teaching method. The analysis of the questionnaire Item 6, "Are you able to answer your peers' questions well with clear explanation and elaboration?" revealed that majority of the students (95.7\%) agreed they could answer all the inquiries relating to their assigned topic. As a matter of fact, these students also claimed that they have helped their peers to better understand the assigned language teaching method through the flipped classroom activity.

In summary, the students' task fulfilment under this flipped classroom approach has not only helped them to improve their poster presentation but also to offer clear explanation and elaboration when handling questions from peers.

TESL Students' Views on the Feasibility of Using Flipped Classroom Approach to Teach Other TESL Subjects

The TESL students' views on the feasibility of using flipped classroom approach to teach other TESL subjects will be discussed in terms of their attitudes towards the approach, their perceptions on the approach, and their suggestions on own self-improvement in terms of learning competency and knowledge. The likelihood of the flipped classroom approach being used for other TESL subjects will depend on the TESL students' attitudes towards the flipped classroom approach. The analysis of questionnaire Item 1 - "I like the way lessons are taught in my class." revealed that all the students (69.6\% agreed and $30.4 \%$ strongly agreed) have positive attitudes towards the flipped classroom approach used in Methodology in TESL 1 class. They liked having the opportunity to research on a topic relevant to the language teaching methodology and present their findings using a poster.

The TESL students total $(100 \%)$ agreement to the questionnaire Item 5 - "I like the idea of learning according to my own pace" indicated that the students liked the flipped classroom approach because it allows them to learn on their own at their own pace. The flipped classroom approach, according to the students, has allowed maximum usage of in-class time. The analysis of questionnaire Item 6 - "I like the way the in-class time is maximised to enable me to learn through peer-to-peer interaction" showed that $97.5 \%$ of the students agreed with this statement. Similarly, the $100 \%$ agreement (30.4\% strongly agreed and $69.6 \%$ agreed) from the students indicated that they like the approach because the in-class time was fully maximised, and they could get more feedbacks from their lecturer.

The students were also asked if the flipped classroom approach has benefitted them in terms of their learning capability or knowledge. Almost all the students agreed that the usage of flipped classroom approach for the Methodology in TESL 1 subject had not only allowed them to learn a lot and improved their knowledge on the language teaching methods and approaches, but it had also taught them how to get help if they have any problem relating to the task fulfilment. In addition, 
majority of the students claimed that they did well for the given task. The following Figure 2 shows the students' responses in relation to the advantages of the flipped classroom approach.

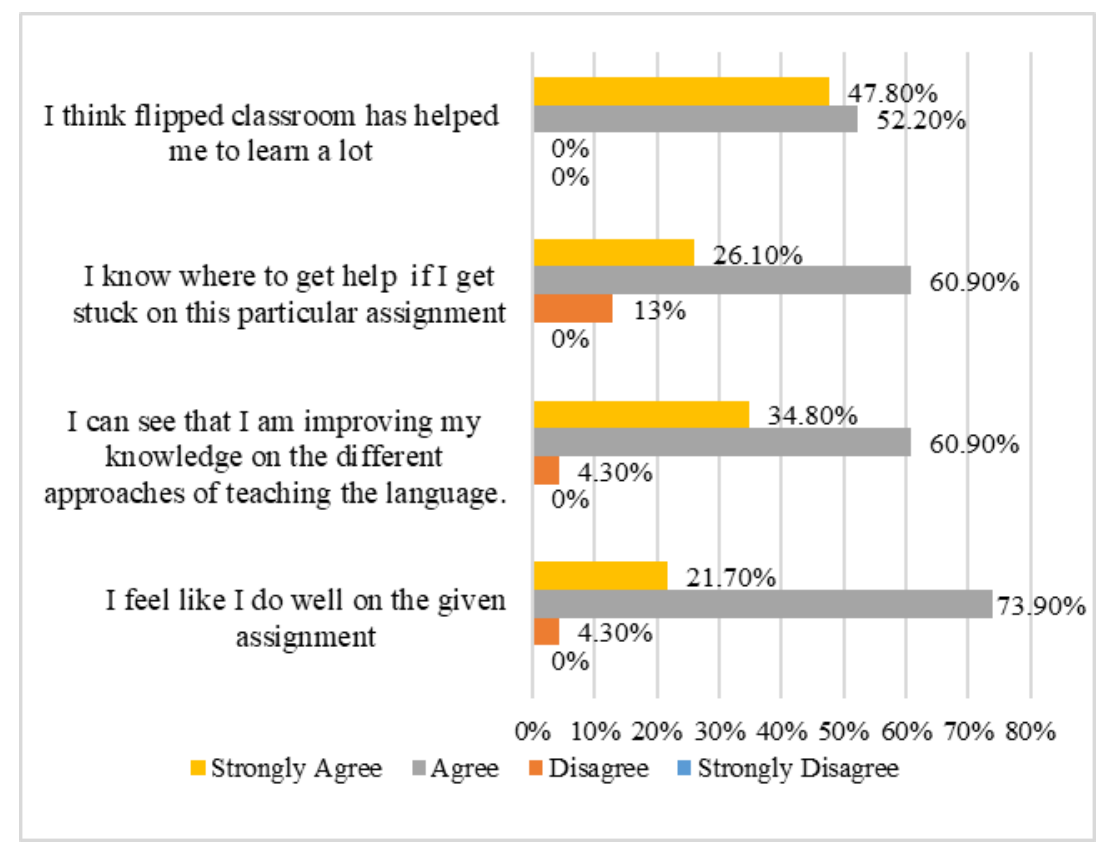

Figure 2 Flipped classroom approach from students'Perspective

Finally, Figure 3 below illustrates the TESL students' responses in relation to the potential usage of flipped classroom approach for other TESL subjects.

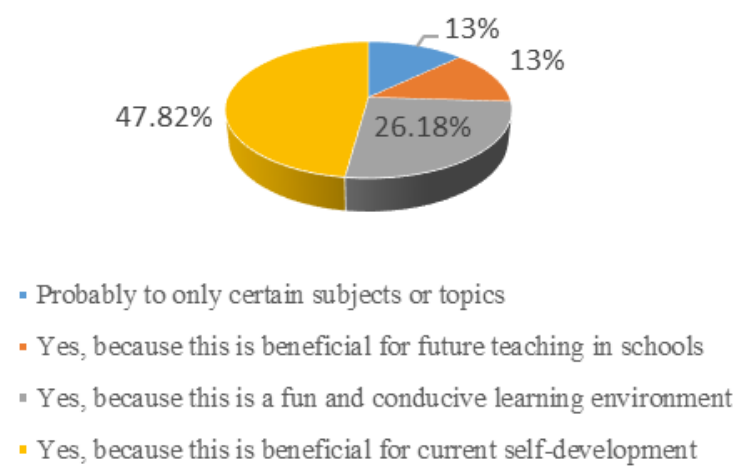

Figure 3 Flipped classroom approach for other TESL subjects 
More than half of the students $(60.82 \%)$ stated the approach should be used for other TESL subjects because it is beneficial for TESL students' future teaching in schools and for the TESL students' current self-development. Another $26.18 \%$ of the students agreed to the usage of this approach for other TESL subjects because it can turn the learning environment to be conducive and fun. Nevertheless, $13 \%$ of the students stated that this approach should only be used for certain TESL subjects and topics.

\section{CONCLUSION}

In conclusion, majority of the TESL students had clearly understood the requirement of the given task and they were able to prepare a poster on the language teaching method assigned to them. With regards to the feasibility of the flipped classroom approach to be used for other TESL subjects, majority of the TESL students felt that the approach could create conducive and fun learning environment besides helping them to self-develop themselves as teachers in schools. However, to avoid inaccurate knowledge being transferred among peers, proper guidance from the lecturer is necessary.

In line with the findings, it was noticeable that although the flipped classroom approach was hardly applied before in the TESL undergraduate programs at this university, the current Covid-19 pandemic has proven that this approach is somehow feasible due to time and face-to-face teaching constraints. The blended learning is considered the key pedagogical innovation where online lessons and flipped classroom approach were able to assist educators of all educational levels to facilitate their students. Through the extensive reading the students have to do and online classroom discussions, they seem to be able to develop their critical and creative thinking skills, thus, leverage their knowledge and skills. Hence, it is recommended that the challenges faced by both teachers and students be investigated when the flipped classroom approach is implemented, especially during the Covid-19 pandemic.

\section{REFERENCES}

Andujar, A., Salaberri-Ramiro, M. S and Crúz Martínez, M. S. 2020. Integrating Flipped Foreign Language Learning through Mobile Devices: Technology Acceptance and Flipped Learning Experience. Sustainability, 12, 1110.

Bell, M. R. 2015. An Investigation of the Impact of a Flipped Classroom Instructional Approach on High School Students' Content Knowledge and Attitudes Toward the Learning Environment. All Theses and Dissertations. Paper 4444.

Cornell Center for Materials Research. (n.d.). Scientific Poster Design. Retrieved on December 5, 2016, from http://www.ccmr.cornell.edu.

Creswell, J. W. 2012. Educational Research: Planning, Conducting and Evaluating Quantitative and Qualitative Research. $4^{\text {th }}$ Ed. Pearson Education, Inc. Boylston Street, Boston, MA 02116. 
Creswell, J. W., and Plano Clark, V. L. 2011. Designing and Conducting Mixed Methods Research. Thousand Oaks, California, USA: Sage.

Creswell, J. W., and Plano Clark, V. L. 2011. Designing and Conducting Mixed Methods Research. Thousand Oaks, California, USA: Sage.

Danker, B. 2015. Using Flipped Classroom Approach to Explore Deep Learning in Large Classrooms. The IAFOR Journal of Education. 3(1): 171-186.

Donnelly, R. 2009. Harmonizing Technology with Interaction in Blended Problem-based Learning. Computers and Education. 54(2), 350-359.

Doi:10.1016/j.compedu.2009.08.012.

Flipped Learning Network (FLN). 2014. The Four Pillars of F-L-I-PTM Gannod, G., Burge, J. and

Helmick, M. 2008. Using the Inverted Classroom to Teach Software Engineering. Paper Presented at the Meeting of the 2008 IEEE International Conference of Software Engineering, Leipzig, Germany.

Grapragasem, S., Krishnan, A. and Mansor, A. N. 2014. Current Trends in Malaysia Higher Education and Effect of Education Policy and Practice: An Overview. International Journal of Higher Education. 3(1): 85-93.

Kawinkoonlasate, P. 2019. Integration in Flipped Classroom Technology Approach to Develop English Language Skills of Thai EFL Learners. English Language Teaching. 12(11): 23-34.

Lage, M. J., Platt, G. J., and Treglia, M. 2000. Inverting the Classroom: A Gateway to Creating an Inclusive Learning Environment. Journal of Economic Education. 31(1): 30-43. http://dx.doi.org/10.2307/1183338.

Miragall, M., \& García-Soriano, G. 2016. Transforming a Class from the Psychology Degree into a Flipped Classroom. @ tic. revista d'innovació educative.17: 21-29.

Oral Presentation Rubric (n.d.). Readwritethink. Retrieved on June, 3, 2016, from http://www.readwritethink.org/files/resources/printouts/30700_rubric.pdf.

National Higher Education Action Plan 2007-2010. Retrieved on June, 3, 2016, from http://planipolis.iiep.unesco.org/upload/

Malaysia/Malaysia\%20Higher\%20education\%20action\%20plan\%202007-2010.pdf.

Vuong, Nguyen Huu Anh, Tan, C. K., Lee, K.W. 2018. Students' Perceived Challenges of Attending a Flipped EFL Classroom in Viet Nam. Theory and Practices in Language Studies. 8(11): 15041510. DOI: http://dx.doi.org/10.17507/tpls.0811.16.

Zeynep Turan \& Birgul Akdag-Cimen. 2019. Flipped Classroom in English Language Teaching: A Systematic Review. Computer Assisted Language Learning.

DOI: $10.1080 / 09588221.2019 .1584117$. 